\title{
Concentrated Language Encounter Instruction Model III in Reading and Creative Writing Abilities
}

\author{
Piyapong Promnont ${ }^{1} \&$ Saowalak Rattanavich ${ }^{2}$ \\ ${ }^{1}$ School of Education, Srinakharinwirot University, Thailand \\ Correspondence: Saowalak Rattanavich, School of Education, Srinakharinwirot University, Bangkok, Thailand. \\ Tel: 66-81-812-4862. E-mail: s_rattanavich@hotmail.com
}

Received: February 4, 2015 Accepted: March 9, 2015 Online Published: April 23, 2015

doi:10.5539/elt.v8n5p1 URL: http://dx.doi.org/10.5539/elt.v8n5p1

\begin{abstract}
The research is aimed to study the development of eleventh grade students' reading, creative writing abilities, satisfaction taught through the concentrated language encounter instruction method, CLE model III. One experimental group time series design was used, and the data was analyzed by MANOVA with repeated measures, $t$-test for one-group samples, basic statistical and line figures in the study. The study's results demonstrate that the experimental group had significantly higher development in English reading and creative writing at a .001 level and registered significantly at a much higher satisfaction at a .001 level.
\end{abstract}

Keywords: concentrated language encounters instruction, reading, creative writing, steps of CLE instruction, and satisfaction after learning

\section{Introduction}

\subsection{Introduce the Problem}

According to a report by the National Institute of Educational Testing Service (NIETS), the Ministry of Education (2014) reported that the average scores of Thai students in O-NET (ordinary national educational test) at secondary schools during the past few years were below the standard at approximately 23.98, 19.22, 21.80, 21.23, and 25.35 out of 100, respectively, in 2009 to 2013 in English as well as other subjects, despite spending twelve years studying English in primary and secondary schools (O-NET report, 2009-2013). In addition, the report by the Programme for International Student Assessment (PISA) showed that the average scores of Thai students ranked $48^{\text {th }}$ for reading, $50^{\text {th }}$ for mathematics, and $48^{\text {th }}$ for science (PISA report, 2012). All reports showed that Thai students were below the standard in English as well as other subjects. A number of Thai educators have identified two factors that cause ineffective teaching and learning of English in the Thai context. First, one of the factors originates from the students themselves. Most Thai students learn English for longer than ten years, yet they have poor English skills due to a lack of English language proficiency. They use little English in daily life because they worry about grammar; therefore, they do not get enough exposure to a variety of learning experiences through practice. In addition, they have very little time to practice English outside of class. Another issue is they lack of motivation in learning English, which is one of the obstacles in their English learning development. Thus, learning English is done only by rote memorization of new words, sentences, and grammatical structures. Therefore, Thai students are just passive receivers of knowledge with opposite in student-centered that they must be (Pawapatchaudom, 2007; Chawwang, 2008; Ministry of Education, 2009; Yoosabai, 2009; Rattanavich, 2009, 2013).

Moreover, Thai English teachers also have poor quality English skills, both spoken and written. A University of Cambridge survey carried out in 2006 measuring the qualifications of four hundred Thai English teachers found that over $60 \%$ had insufficient knowledge of English and teaching methodologies below that of the syllabus level at which they were teaching and that $40 \%$ had passing knowledge and teaching skills, while only $3 \%$ had a reasonable fluency in English (Education in Thailand, 2013). This is mainly because most Thai English teachers speak predominately Thai during class, use the grammar translation method, and other teacher-centered methods. They taught vocabulary, especially with a grammatical focus in class. Even though the Ministry of Education supports training in current trends, such as CLT, student-centered, or other active learning techniques, English teachers find it difficult to adopt new approaches or teaching techniques because they lack the communication skills required. Moreover, some of the teachers have heavy teaching loads, inadequately equipped classrooms, 
and a lack of educational technology (Noom-ura, 2013; Rattanavich, 2013; Ministry of Education, 2014).

In 2014, the Ministry of Education announced policies to reform teaching and learning English at the basic education level using the international standard of the common European framework of reference for languages (CEFR) as the main yardstick for managing teaching and learning the English language, adapting the teaching and learning of English by focusing on communicative language teaching (CLT), promoting English teaching and learning by expanding special projects in teaching, and learning English in order to use information computer technology (ICT) media for education as a tool to develop the abilities of teachers and students and to enhance the teaching and learning management skills and knowledge of teachers (Ministry of Education, 2014 cited in Yamwagee, 2014). There is an urgent need to conduct an effective English teaching method for students who will soon learn in a university, preparing them for an Asian Economic Community (AEC) in 2015 and for working in the global marketplace.

Taking the problems as discussed into consideration, many studies suggest CLE instruction. The CLE instruction has been successfully replicated in several countries in Africa, the Philippines, Nepal, India, Egypt, Pakistan, Bangladesh, Laos, Cambodia, Turkey, and Thailand, and have shown the same results; students are able to communicate both in spoken and written in English as well as in the mother tongue. Thus, the CLE model III is an alternative method for solving the issues in learning and teaching English. The CLE model III begins with a reading stage and continues through a writing task stage systematically. Students participate in learning activities, which include both individual and group work, and students also have a chance to employ all their skills. The goal of the CLE model III is to gain comprehensible input from a learning process in which students experience using scientific methods of discovering information regarding a range of subject matter within their regular studies and can report what they discover (Walker et al., 1992; Lopeung, 2012). According to many studies, CLE model III can solve English teaching and learning problems in all of the skills: reading, writing, listening, and speaking (Termsinsuk, 1992; Thongprim, 2003; Lopeung, 2012). For example, the results of Thongprim's study (2003) showed that the student English proficiency in reading and writing gained using the CLE instruction model III was significantly higher than when using conventional teaching, and the CLE instruction model III can promote student reading and writing satisfaction. Furthermore, the study by Rattanavich (2007) synthesized the effectiveness of the CLE instruction as the treatment compared to traditional instruction. A meta-analysis was done on 76 graduate student research studies on CLE instruction in Thai and English programs during 1989 to 2004 and found that the CLE instruction model demonstrated a much higher percentage of achievement in language performance than those taught through a traditional teaching program. For example, secondary students learning English through the CLE instruction model III showed higher average scores than the control group student scores of about 94.52 percent $(\overline{\mathrm{d}}=1.60)$ in language performance, 75.80 percent $(\overline{\mathrm{d}}=3.18)$ in attitudes, and 92.36 percent $(\overline{\mathrm{d}}=1.43)$ in personality development. However, all of the studies showed that the CLE instruction model III can promote English performance and reduce learning problems for Thai students.

\subsection{Research Questions}

1) Is there a significant improvement in reading and creative writing based on a study of the experimental group after being taught through the CLE instruction model III?

2) Is the eleventh grade students' satisfaction on CLE instruction model III significantly boosted after the training?

\subsection{Objectives of the Study}

1) To study the development of eleventh grade students' reading and creative writing abilities after being taught through the CLE instruction model III.

2) To study eleventh grade student satisfaction after learning through the CLE instruction model III.

\section{Literature Review}

\subsection{Theoretical Assumptions of Concentrated Language Encounter Instruction}

Many researchers have been doing research to investigate appropriate teaching approaches, techniques, and instructional tools to help students have better English skills, especially reading and writing. Among many instructions, Concentrated Language Encounter Teaching Technique or CLE developed by Gray is of research interest. The term "concentrated language encounters" originated from Courtney Cazden, who made the point that children learn language mainly through encounters with others in which children concentrate intensely on making themselves understood (Walker et al., 1992, pp. 12-13). In addition, the most successful teaching sessions were those in which students were put in a situation where they were doing interesting and useful activities, but where they had to confront challenging language tasks to achieve those aims. Essentially, the first 
principle of the CLE is an immersion program in which children are constantly involved in doing new and ever more challenging activities using language. A second principle is that of scaffolding, where the teacher models what the students are expected to do and supports what they need to accomplish. This process utilizes the teacher in a critical role in scaffolding to model appropriate models of the language, and engages the students in developing and using necessary language skills (Rattanavich, 2013, p. 131). A third principle is that all language is activity-based learning. The students understand the meaning of what they read or write and understand what they are expected to do. This helps the learner to understand the meaning of what is said or written. The students learn language through their own thinking process and are able to communicate in spoken and written modes on their own (the GM South Africa Foundation, 2009). The CLE also is aimed at encouraging the students to use spontaneous oral language relevant to the topic through language encounters in the classroom context. These language encounters may be in the form of role play, dialogue, or discussion about an experience or a story shared by the teacher and children, and the students also independently produce a text based on the text they have read, discussed, and performed with guidance and support from their teacher (Northern Territory Department of Education, 1985, cited in Prasongsuk, 2011, p. 43). The teaching approaches related to the CLE instruction focus on the following:

1) The natural approach is a real, natural student-centered learning process in which students experience their language skills through their own thinking process in the way humans naturally acquire their native language. Meaningful input is an important component for children's understanding, which enables students to communicate with their parents. Furthermore, the natural approach also points out the language elements in a naturally integrated way covering contextual meaning, different types of text structures, functional grammatical points, and idiomatic words or sentences of the language (Lopeung, 2012, p. 14; Rattanavich, 2013, pp. 31-32). The learning and language process focuses on the need for comprehensible input using appropriate teaching for student language acquisition (Krashen \& Terrell, 1983).

2) The genre-based approach focuses on the schematic structure and linguistic feature theory that is used in context in different communications to understand text. Different genres have different purposes for conveying spoken or written messages in different situations, such as recounting, reporting, discussing, explaining, narrating, exposing, interviewing, observing, etc. In each genre there is, therefore, a pattern of linguistic features used. Understanding the genres in different contexts can help students, especially second language students, to learn a schematics structure or text organization and linguistics features both in spoken and written language texts. The goal of the genre is to help students to gain access to mainstream genres. Students will be provided with explicit knowledge or a relevant genre so that they can act effectively in their target context (Hyland, 2002, cited in Payaprom, 2012, p. 32, Rattanavich, 2013, pp. 50-62).

3) The communicative approach is to enable students to use all four skills that are based on the idea that learning language successfully comes through having to communicate real meaning. The students have a chance to practice their language by themselves, but the teacher gives the correct language to students from the starter text to promote students to use spoken and written language in daily life (Rattanavich, 2013, p. 67)

\subsection{Phases of Instruction in CLE Stages}

The CLE has three stages of primary schooling - the lower, middle, and upper grades as follows (Rattanavich, 1992, pp. 13, 20, 25):

1) Stage 1 of the program: the lower primary school grade is for beginning school students to become enthusiastic readers and writers. At the end of stage 1, they should be able to read various types of simple texts and to recall and talk about what is contained in the text that they read. A stage 1 CLE program usually covers two or three years, depending on whether or not it is used in a preschool or kindergarten class.

2) Stage 2 of the program: this is the method used to teach students who have language experience. The middle primary school grades have the students analyze the model text to come to understand its uses and characteristics and then to compose and use a text for themselves.

3) Stage 3 of the program: the upper primary school is intended to cover the last few years of primary school to give students experience in using scientific methods of discovering a range of subject matter within their regular studies and report on what they have discovered. 
2.3 Steps of Instruction in CLE Model III (Rattanavich, 1992)

1) Orientation

a) Contextualization

b) Mapping the topic

c) Surveying the text organization

d) Establishing the genre of the text being read and the text to be written

e) Dealing with unfamiliar vocabulary

2) Reflections: students need to produce a writing plan from reflecting on both what is required of them in the writing task and what is available from the text.

3) Note-taking

a) Each student fills in an individual writing plan with information that was noted from reading the text.

b) Groups reconvene to negotiate a common set of notes for the group.

4) Synthesizing new text: students write a first draft of a text that aims to realize the writing task goal.

5) Editing

a) Reviewing: students examine their texts for adequacy and suitability in relation of the task goal.

b) Redrafting: students redraft their texts in the light of the review.

c) Polishing: the teacher may lead the whole group to polishing a group text, discussing ways of eliminating surface weaknesses.

6) Final copy and elaboration.

a) Final copy: students discuss what physical properties are needed to best serve the text purposes and then produce a final copy.

b) Elaboration: the teacher organizes independent activities for groups of students or individuals in some aspect of reading and writing.

\subsection{Hypotheses of the Study}

1) A study of the development of eleventh grade students' reading and creative English writing abilities taught through CLE instruction model III would result in post-test (1) and post-test (2), which are higher than the pretest.

2) The eleventh grade students that are taught through CLE instruction have higher satisfaction in learning.

\section{Methodology}

In the study, the researcher attempts to study the effects of eleventh grade students' studying reading, creative English writing abilities, and satisfaction in learning when taught through CLE instruction model III. The research procedures follow.

\subsection{Research Design}

One group time series design was used in the study. The sample group was taught through the CLE instruction model III in 15 weeks with 30 teaching hours, including a pretest and a post-test session.
$\begin{array}{lllll}\mathrm{E} & \mathrm{T}_{1} & \mathrm{X} & \mathrm{T}_{2} & \mathrm{~T}_{3}\end{array}$
$\mathrm{E}=$ Experimental group
$\mathrm{T}_{1}=$ Pretest
$\mathrm{X}=\mathrm{CLE}$ Instruction Model III
$\mathrm{T}_{2}=$ Posttest 1
$\mathrm{T}_{3}=$ Posttest 2

\subsection{Population and Sample}

The participants in this study were eleventh grade students $(n=43)$ enrolled in the elective course "Reading and Writing English" in the first semester of academic year 2014 at Triamudomsuksanomklao School, Bangkok and were purposely selected as the sample of this study. 


\subsection{Research Instruments}

Two kinds of instruments (the tests and the questionnaire) were used in the study. Two multiple-choice and cloze reading equivalency tests (with a reliability of 0.81 and 0.83 calculated by Pearson's correlation coefficient), one creative writing test (with a reliability of 0.63 calculated by Cronbach's alpha coefficient), and five-choice Likert scale questionnaires on satisfaction about learning through the CLE instruction model III (with a reliability of 0.92 calculated by Cronbach's alpha coefficient) were used in the study.

\subsection{Data Analysis}

Each hypothesis was tested using a computer program as follows:

Hypothesis 1: The scores were compared regarding the two tests for reading and one test for creative writing of the experimental group's pretest and the other two post-tests using MANOVA with repeated measures for within group analysis through the processes of a univariate test, multivariate test, simple effect analysis, and analysis of effect size for the results of the treatment in the experimental group $\left(\right.$ Partial $\left.\eta^{2}\right)$. Finally, line figures were used for a summary of the results of the data analyses.

Hypothesis 2: The data of the experimental group was analyzed using basic statistical analyses ( $\bar{X}$ and S.D.), and the satisfaction results were finalized using the rating criteria (least, little, moderate, much, and most). For one group samples the $t$-test was used to compare the significance of the experimental group.

\section{Results}

The results of the study correspond to the two questions as follows;

The results of the first question "Is there a significant improvement in reading and creative writing based on a study of the experimental group after being taught through the CLE instruction model III?" are shown in Tables 1 through 3.

Table 1. Test of reading and creative writing abilities of the experimental group through the analysis of MANOVA with repeated measures $(n=43)$

\begin{tabular}{lllll}
\hline Variables & \multicolumn{4}{l}{ Multivariate Test } \\
\hline Reading & $\mathrm{n}$ & Wilks'Lambda & $\mathrm{F}$ & $\mathrm{p}$-value \\
Creative writing & 43 & .753 & $9.544^{* * *}$ & .000 \\
\hline
\end{tabular}

*** p-value $<.001$.

The data presented in Table 1 indicates that the experimental group registered significantly in reading and creative writing in English at a .001 level after being taught through the CLE instruction model III (multivariate $\Lambda=.753$, F-statistic $=9.544$, p-value $=.000$ ), and Figure 1 showed that the experimental group had more development in reading and creative writing in English after the training.

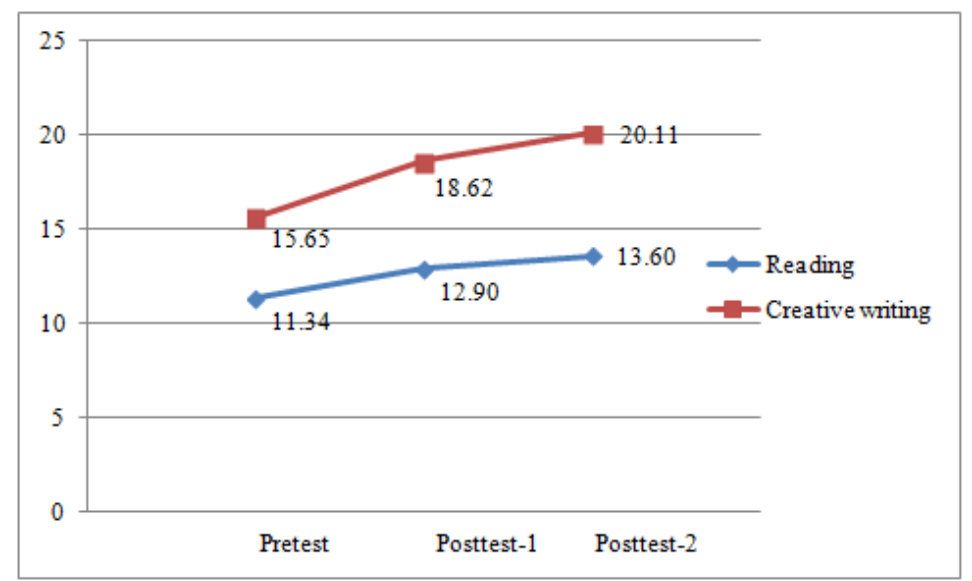

Figure 1. Comparison of the development in reading and creative writing of the experimental group shown by line figure 
Table 2. Test of the development in reading of the experimental group through the analysis of ANOVA with repeated measures

\begin{tabular}{|c|c|c|c|}
\hline \multirow{2}{*}{ Reading } & \multicolumn{3}{|c|}{ Variables } \\
\hline & Pretest & Post-test 1 & Post-test 2 \\
\hline $\operatorname{Mean}(\bar{X})$ & 11.34 & 12.90 & 13.60 \\
\hline Standard Deviation (S.D.) & 3.45 & 3.09 & 3.53 \\
\hline \multicolumn{4}{|c|}{$\Lambda=.681$ F-statistic $=9.594 * * * \mathrm{p}$-value $=.000$} \\
\hline \multirow{3}{*}{ Univariate Test } & \multicolumn{3}{|c|}{$\begin{array}{l}\mathrm{F}_{(\text {pretest-Posttest 1) }}=1.558^{* *} \\
\mathrm{p} \text {-value }=.002\end{array}$} \\
\hline & & \multicolumn{2}{|c|}{$\begin{array}{l}\mathrm{F}_{(\text {Posttest 1-Posttest 22 })}=.698 \\
\mathrm{p} \text {-value }=.601\end{array}$} \\
\hline & \multicolumn{3}{|c|}{$\begin{array}{l}\mathrm{F}_{\text {(Pretest-Posttest 2) }}=2.256^{* * *} \\
\mathrm{p} \text {-value }=.001\end{array}$} \\
\hline
\end{tabular}

Treatment effects

CLE Instruction model III

Partial $\eta^{2}=.319$

(Effect size)

** $\mathrm{p}$-value $<.01$.

$* * *$ p-value $<.001$.

In Table 2, the comparison of the development in reading indicated that the experimental group registered higher development in reading at a .001 level $(\Lambda=.681 \mathrm{~F}$-statistic $=9.594$, p-value $=.000)$. A univariate test comparison between pretest and post-test 1 was significant at $.01(\mathrm{~F}$ (pretest-Posttest 1$)=1.558, \mathrm{p}$-value $=.002)$, pretest and post-test 2 was significant at $.001\left(\mathrm{~F}_{\text {(Pretest-Posttest 2) }}=2.256, \mathrm{p}\right.$-value $=.001$, and post-test and post-test 2 was not significant $\left(\mathrm{F}_{(\text {Posttest 1-Posttest 2) }}=.698\right.$, p-value $\left.=.601\right)$.

Table 3. Test of the development in creative writing of the experimental group through the analysis of ANOVA with repeated measures

\begin{tabular}{|c|c|c|c|}
\hline \multirow{2}{*}{ Creative Writing } & \multicolumn{3}{|c|}{ Variables } \\
\hline & Pretest & Post-test 1 & Post-test 2 \\
\hline $\operatorname{Mean}(\bar{X})$ & 15.65 & 18.62 & 20.11 \\
\hline Standard Deviation (S.D.) & 3.54 & 3.15 & 3.16 \\
\hline \multicolumn{4}{|c|}{$\Lambda=.244$ F-statistic $=63.561 * * * p$-value $=.000$} \\
\hline \multirow{3}{*}{ Univariate Test } & \multicolumn{3}{|c|}{$\mathrm{F}_{\text {(pretest-Posttest 1) }}=2.977 * * *$} \\
\hline & & \multicolumn{2}{|c|}{$\begin{array}{l}\mathrm{F}_{\text {(Posttest 1-Posttest 22 })}=1.488^{* * *} \\
\mathrm{p} \text {-value }=.000\end{array}$} \\
\hline & \multicolumn{3}{|c|}{$\mathrm{F}_{\text {(Pretest-Posttest 2) }}=4.465 * * *$} \\
\hline
\end{tabular}

Treatment effects

CLE Instruction model III

Partial $\eta^{2}=.756$

(Effect size)

$* * * \mathrm{p}$-value $<.001$. 
In Table 3, the comparison of the development in creative writing indicated that the experimental group registered higher development in creative writing at a .001 level $(\Lambda=.244 \mathrm{~F}$-statistic $=63.561$, p-value $=.000)$. The univariate test comparison between the pretest and post-test 1 was significant at $.001\left(\mathrm{~F}_{\text {(pretest-Posttest 1) }}=2.977\right.$, $\mathrm{p}$-value $=.000)$, pretest and post-test 2 was significant at $.001(\mathrm{~F}$ (Pretest-Posttest 2) $=4.465$, p-value $=.000)$, and post-test and post-test 2 was significant $\left(\mathrm{F}_{\text {(Posttest 1-Posttest 2) }}=1.488\right.$, p-value $\left.=.000\right)$.

The findings in Tables 1 to 3 demonstrate the conclusion that the experimental group registered significance in reading and creative writing in English at a .001 level. After the training, the experimental group improved their reading by $31 \%$ with a significance at a .001 level and improved their creative writing by $75 \%$ with a significance at a .001 level after learning through the CLE instruction model III.

The results of the second question "Is the eleventh grade students' satisfaction on CLE instruction model III significantly boosted after the training?" are shown in Tables 4 and 5.

Data presented in Tables 4 and 5 showed that the experimental group registered a significantly higher satisfaction at a .001 level after learning through the CLE instruction model III.

Table 4. Test of significance in the overall satisfaction regarding learning through CLE instruction model III in the experimental group using $t$-test for one group samples

\begin{tabular}{lllllll}
\hline & $\mathrm{n}$ & \multicolumn{3}{c}{ Satisfaction } & \multirow{2}{*}{$\mathrm{t}$} & \multirow{2}{*}{$\mathrm{p}$-value } \\
\cline { 3 - 5 } & & $\bar{X}$ & S.D. & & \\
\hline Experimental group & 43 & 3.81 & 0.89 & $6.073^{* * *}$ & .000 \\
\hline
\end{tabular}

$* * *$ p-value $<.001$.

Table 5. Analysis of basic statistical data in the experimental group's satisfaction on learning through CLE instruction model III

\begin{tabular}{|c|c|c|}
\hline \multirow{2}{*}{ Satisfaction } & \multicolumn{2}{|c|}{ Experimental group } \\
\hline & $\bar{X}$ & S.D. \\
\hline 1) The text is not too difficult to apply in daily life. & 3.41 & 0.86 \\
\hline 2) The learning process in this course enables me to understand through the program. & 3.43 & 0.89 \\
\hline $\begin{array}{l}\text { 3) The learning process in this course is very interesting and attractive to me for ongoing } \\
\text { learning. }\end{array}$ & 3.46 & 0.92 \\
\hline $\begin{array}{l}\text { 4) In this course, there were well-prepared learning materials that enabled me to } \\
\text { understand a lesson quickly. }\end{array}$ & 3.41 & 0.94 \\
\hline 5) In this learning process, the teacher is able to explain and give examples clearly. & 3.56 & 0.92 \\
\hline 6) I enjoy learning in the class; it is not boring. & 3.90 & 1.09 \\
\hline $\begin{array}{l}\text { 7) I prefer to join English activities because I have opportunities to practice my skills in } \\
\text { a wider variety of issues or content areas. }\end{array}$ & 3.75 & 0.88 \\
\hline 8) The learning activities in this course enable me to be an active learner. & 3.58 & 0.83 \\
\hline $\begin{array}{l}\text { 9) I enjoy the steps of teaching in this course, which encourage me to construct, analyze, } \\
\text { and solve a problem creatively. }\end{array}$ & 3.58 & 0.92 \\
\hline $\begin{array}{l}\text { 10) The learning in this course encourages me to participate in various activities like } \\
\text { games, oral presentations, sharing ideas, etc. }\end{array}$ & 3.60 & 0.97 \\
\hline 11) I have opportunities to practice by myself in the learning process. & 3.82 & 0.89 \\
\hline $\begin{array}{l}\text { 12) The learning processes in this course are useful for enabling me to develop both } \\
\text { spoken and written skills in English and subject areas. }\end{array}$ & 3.78 & 0.90 \\
\hline 13) I feel that I can better develop English in vocabularies, idioms, symbols, etc. & 3.87 & 0.92 \\
\hline 14) I feel that I can use English to apply information/knowledge/news from this course. & 3.73 & 0.97 \\
\hline
\end{tabular}


15) The learning gained in reading and writing in English through the CLE model III is useful to me.

$3.97 \quad 0.96$

16) I can apply the learning process from this course through CLE model III in the future.

17) I feel that I can write better in English on various topics.

18) I have more opportunities for listening and speaking in this course.

$3.92 \quad 0.81$

19) I feel more self-confident in communication/interpretation of English with others.

$3.63 \quad 0.76$

$3.70 \quad 0.90$

20) I enjoy planning and doing the mapping and graphic organizers to promote the ability to summarize the text.

21) I enjoy learning with friends and the teacher in this course.

$3.63 \quad 0.91$

22) I like to do the activities with friends and others.

$3.78 \quad 0.93$

$3.82 \quad 0.99$

23) The learning process of CLE instruction model III helps me to develop reading and writing skills in English.

$3.92 \quad 0.84$

24) I am very satisfied regarding learning through the CLE instruction model III.

Total

$3.85 \quad 0.79$

$3.81 \quad 0.89$

Table 6. Criteria for data interpretation

\begin{tabular}{ll}
\hline Criteria & Level of satisfactions \\
\hline $4.21-5.00$ & Most \\
$3.41-4.20$ & Much \\
$2.61-3.40$ & Moderate \\
$1.81-2.60$ & Little \\
$1.00-1.80$ & Least \\
\hline
\end{tabular}

\section{Discussion and Conclusion}

The results of the study are useful in the field of teaching English language reading and creative writing using the CLE instruction model III.

The experimental group registered significant results in reading, creative writing, and student satisfaction in learning. The results of this study may be explained by eleventh grade students having significantly more development in English, especially in reading and writing skills. The experimental group may be able to read and create their own writing following the CLE model III procedure due to the steps of teaching the CLE instruction model III; students begin with reading and transition to writing following the nature of language. They have trained in reading until they have obtained reading strategies. They not only know how to read, but also are able to understand schematic structures as well as linguistic features in both spoken and written language. When students practice reading enough, they can be good writers because they can identify the main idea, symbols, idioms, etc. of the text. In addition, while the students read, they can memorize the correct schematic structures and linguistic features of different types of text, which assists students to read and plan their own writing. This has assisted students developing improved proficiency in reading and writing skills. In addition, the learning process of the CLE instruction model III focuses on student experience, giving more opportunity to take risks of using language by themselves under the teacher's supervision and assistance through scaffolding techniques.

Also, according to the findings, the post-test mean scores of the experimental group that was taught through the CLE instruction model III were higher than the pretest scores in both reading (11.34, 12.90, and 13.60, respectively) and creative writing $(15.65,18.62$, and 20.11, respectively). The findings emphasized that the CLE instruction model III enabled the experimental group to improve English reading and creative writing skills. The findings correspond to the results of many studies on CLE literacy in Thailand and elsewhere, which have shown the same results that students are able to communicate in English in reading and writing, including to listening and speaking in English as well as in the mother tongue. In addition, students taught through the CLE instruction model III had more motivation, satisfaction, responsibility, and interest in learning English after using this 
method (Termsinsuk, 1992; Borpitsuwan, 1994; Thongprim, 2003; Panraung, 2006; Lopeung, 2012).

After studying the development of the experimental group based on the results of this study, it can be concluded that the experimental eleventh grade student group taught through the CLE instruction model III can improve their English in reading and creative writing skills significantly. The experimental eleventh grade group of students also registered a significantly higher satisfaction rating after learning through the CLE instruction model III.

\section{Acknowledgements}

The author gratefully acknowledges to Associate Professor Dr. Saowalak Rattanavich, Dr. Pornpimon Prasongporn, and Dr.Wilailak Langka from the School of Education, Srinakharinwirot University for their kind guidance, valuable comments, and encouragement throughout the study. I also gratefully acknowledge the Graduate School, Srinakharinwirot University, for their financial support in conducting this study.

\section{References}

Borpitsuwan. (1992). A Comparison of Writing Ability and Motivation in Thai writing of Mathayousuksa II students through the Concentrated Language Encounters (CLE) and the instruction in the Teacher's manual (M.Ed. Thesis, Bangkok: Graduate School, Srinakharinwirot University).

Chawwang, N. (2008). An Investigation of English Reading Problems of Thai 12th-Grade Students in Nakhonratchasima Educational Regions 1, 2, 3, and 7 (M. A. Thesis, Bangkok: Graduate School, Srinakharinwirot University).

Education in Thailand. (2014). English language education in Thailand: Thai teachers. Retrieved September, 2014, from http://en.wikipedia.org/wiki/Education_in_Thailand

Krashen, S. D., \& Terrell, T. D. (1983). The Natural Approach: Language Acquisition in the Classroom. Oxford: Pergamond.

Lopeung, S. (2012). Effects on the Concentrated Language Encounter Instruction (Model III) on Mattayomsuksa 5 Students' Writing Ability (M.A. Thesis, Bangkok: Graduate School, Srinakharinwirot University).

Ministry of Education. (2009). The Report of Thai Educational Condition Roots of problems and solutions. Bangkok, V.T.C. Communication published.

Ministry of Education. (2014). Resolution Leaning and Teaching English Policies on January, 14, 2014.

Noom-ura, S. (2013). English-Teaching Problems in Thailand and Thai Teacher's Professional Development Needs. Journal of English Language Teaching, 6(11), 139-147. http://dx.doi.org/10.5539/elt.v6n11p139

Panraung. (2003). A Comparative study of Mathayomsuksa II student's Thai Reading comprehension, Writing ability and Attitude toward learning Thai Acquired through the Concentrated Language Encounters and the Teacher's manual (M.Ed. Thesis, Bangkok: Graduate School, Srinakharinwirot University).

Pawapatcharaudom, R. (2010). An Investigation of Thai Students' English Language Problems and Their Learning Strategies in the International Program at Mahidol University (M.A. Independent study). King Mongkut's Institute of Technology North Bangkok, Thailand.

Payaprom, S. (2012). The impact of genre-based approach on English language teaching in an EFL tertiary context in Thailand (Dissertation, University of Wollongong, Australia).

Prasongsuk, S. (2011). Teaching and learning English at the grade 3 level of primary school in Thailand: Evaluating Effectiveness of the three teaching methods (Dissertation, University of Canberra, Australia).

Rattanavich, S. (2007b, September). A Synthesis of Graduate Students' Research Study Results in Thailand Universities concerning Thai and English Language Learning-Teaching Organization through Concentrated Language Encounters. Educational Research Journal. Faculty of Education, Srinakharinwirot University.

Rattanavich, S. (2009, October). The Effects of Brain-Based Autonomous Language Learning Program Developed through a Genre-based Approach for Teacher of English. Educational Research Journal. Faculty of Education, Srinakharinwirot University.

Rattanavich, S. (2013). Concentrated Language Encounter Instruction: Strategies to Success in the Development of Literacy for All (3rd ed.). Bangkok: The Rotary Foundation in Thailand.

Rattanavich, S. (2013b, September). Comparison of Effects of Teaching English to Thai Undergraduate Teacher-Students through Cross-Curricular Thematic Instruction Program Based on Multiple Intelligence Theory and Conventional Instruction. Journal of English Language Teaching, 6(9), 1-18. 
http://dx.doi.org/10.5539/elt.v6n9p1

Termsisuk, S. (1992). A comparative Study of Mattayomsuksa V Students' English Reading and Writing Abilities and Responsibility through the Third model Concentrated Language Encounter Teaching and through the Method in the Teacher's Manual (M.Ed. Thesis, Bangkok: Graduate School, Srinakharinwirot University).

Test and score data summary for TOEFL iBT ${ }^{\circledR}$ tests and TOEFL ${ }^{\circledR}$ PBT tests. (2012). Retrieved September, 2014, from http://www.ets.org/s/toefl/pdf/94227_unlweb.pdf

Test and Scores data summary for TOEFL iBT $^{\circledR}$ Tests. (2013). Retrieved September, 2014, from http://www.ets.org/s/toefl/pdf/94227_unlweb.pdf

The GM South Africa Foundation. (2009). Concentrated Language Encounter: A Proven and effective method for teaching reading. The GM South Africa Foundation published.

The National Testing Bureau, Ministry of Education. (2013). The Report of national test for basic education level (O-NET) 2013 academic year. Retrieved December 5, 2013, from http://www.niets.or.th

Thongprim, S. (2003). A comparative Study of Mattayomsuksa 4 Students'English Reading and Writing Abilities and Interest through the Third model Concentrated Language Encounter Teaching and through the Teacher's Manual Method (M.Ed. Thesis, Graduate School, Silpakorn University).

Walker, R. F., Rattanavich, S., \& Oller, J. (1992). Teaching all the children to read: Concentrated language encounter techniques. Buckingham: The Open University Press.

Yamwagee, N. (2014). Policy to Reform Teaching and Learning the English Language. Retrieved September 9 , 2014, from http://www.thailandteaching.asia/

Yoosabai, Y. (2009). The Effects of Reciprocal Teaching on English Reading Comprehension in a Thai High-School Classroom (Ph.D. dissertation, Bangkok: Graduate School, Srinakharinwirot University).

\section{Copyrights}

Copyright for this article is retained by the author(s), with first publication rights granted to the journal.

This is an open-access article distributed under the terms and conditions of the Creative Commons Attribution license (http://creativecommons.org/licenses/by/3.0/). 